\title{
Comparative analysis of thyroid function parameters in pregnant women
}

\author{
FENG REN $^{1}$, HUAN ZHOU ${ }^{1}$, MIN CHEN $^{1}$, XIANQIU XIAO $^{2}$ and XIAOPING RUI ${ }^{2}$ \\ ${ }^{1}$ Department of Clinical Laboratory, The Affiliated Hospital of Jiangnan University, \\ The Fourth People's Hospital of Wuxi, Wuxi, Jiangsu 214062; ${ }^{2}$ Department of Thyroid and Breast Surgery, \\ The 101st Chinese People's Liberation Army Hospital, Wuxi, Jiangsu 214000, P.R. China
}

Received April 23, 2017; Accepted June 9, 2017

DOI: 10.3892/br.2017.992

\begin{abstract}
The aim of the present study was to investigate the serum levels of free triiodothyronine (FT3), free thyroxine (FT4) and thyroid stimulating hormone (TSH) during pregnancy and comparative analysis of serum markers levels in non-pregnant women and pregnant women. Pregnant women were divided into four groups according to their gestational age: 8-14, 15-20, 21-36 and $\geq 37$ weeks. Non-pregnant women were divided into three groups according to their age: $20-40,41-55$ and 56-85 years, and women of reproductive age (20-40 years) as control, which match their age and body mass index with pregnant women. The levels of serum markers were measured by magnetic microparticle chemiluminescence immunoassay and compared among different gestational weeks or with the control. In pregnant women, from 8-14 to $\geq 37$ weeks, FT3 and FT4 levels declined, and significant differences were identified between each group, except for FT4 at 21-36 weeks, when compared with $\geq 37$ weeks. While TSH was increased and significant differences were identified between each group. Compared with the control group, the concentrations of FT3, FT4 and TSH were lower in pregnant women for all weeks except for TSH in $\geq 37$ weeks. Reference intervals of FT3, FT4 and TSH in pregnant women are much lower than that of the control women. Pregnant women are likely to have lower thyroid hormone levels throughout pregnancy. The current reference intervals of thyroid hormones were not feasible for pregnant women and pregnancy-specific reference intervals should be established according to a local Chinese pregnant women database.
\end{abstract}

Correspondence to: Dr Feng Ren, Department of Clinical Laboratory, The Affiliated Hospital of Jiangnan University, The Fourth People's Hospital of Wuxi, 200 Huihe Road, Wuxi, Jiangsu 214062, P.R. China

E-mail:wxsyrf10@163.com

Key words: thyroid function, free triiodothyronine, free thyroxine and thyroid stimulating hormone, pregnancy

\section{Introduction}

The importance of thyroid function during pregnancy had been recognized long ago $(1,2)$. Thyroid function tests, most commonly including free triiodothyronine (FT3), free thyroxine (FT4) and thyroid stimulating hormone (TSH), are widely used to diagnose thyroid disorders (3). Previously, increasing numbers of studies have demonstrated that maternal thyroid hormones are essential for fetal development during pregnancy, and their deficiency can influence the pregnancy outcome and developing fetus $(4,5)$. Monen et al (6) reported that increased TSH and decreased FT4 are associated with more operative vaginal deliveries and caesarean sections. León et al (7) reported that high maternal FT4 levels during the first half of pregnancy were related to lower birth weight and increased risk of small gestational age newborns. Avoiding maternal thyroid disorders is of major importance because of potential damage to fetal brain development, an increased incidence of miscarriage, preterm delivery or fetal mortality $(8,9)$. Therefore, it is very important to evaluate thyroid function accurately during pregnancy.

The regulation of maternal thyroid function is complex and varies with each stage of pregnancy. During pregnancy, several physiological changes in pregnant women induce complex endocrine and immune responses that, conversely, may affect the course of pregnancy (10). The body automatically adjusts the thyroid hormone concentrations changes through concentrated iodine and achieves the new equilibrium state. This equilibrium is difficult to achieve when iodine supplementation is deficient (11). However, excessive levels of iodine intake may potentially cause more disease (12). Normally, maternal thyroid function tends to adjust itself and these adjustments may range from physiological adaptation to pathological derangement. Previously, researchers recommended the use of pregnancyspecific reference intervals to evaluate maternal thyroid function, which alleviate the misinterpretation of thyroid function in pregnancy. If a non-pregnant reference range is used, many maternal thyroid diseases could be potentially misclassified (13). As a result, maternal thyroid hormones assessment should be performed using pregnancy-specific reference ranges ideally based on locally pregnant women data.

There is a significant difference in the biochemical marker distribution in each stage of pregnancy. Therefore, the aim of 
the present study was to investigate thyroid hormones levels (FT3, FT4 and TSH) during pregnancy and compare with those in women of reproductive age. Initially, the authors analyzed thyroid hormone parameters including mean, median, interquartile range (IQR), 2.5 th percentile (P2.5) and 97.5 th percentile (P97.5) during pregnancy. Then, the authors established a series of reference intervals of thyroid hormones during pregnancy according to their gestational ages. In addition, parameters of thyroid function between pregnancy women and control women of reproductive age were comparatively analyzed.

\section{Materials and methods}

Pregnant women. The present study was conducted in the Fourth People's Hospital of Wuxi, (Wuxi, China) between February 2010 and June 2014. The study consisted of 4,903 pregnant women who were regularly checked into the hospital during pregnancy, and 1,298 non-pregnant women who underwent routine health examination. Serum samples of pregnant women were divided into four groups according to gestational age: i) A total of 849 in the 8-14 week group, ii) 1,655 in the 15-20 week group, iii) 1,247 in the 21-36 week group and iv) 1,152 in the $\geq 37$ week group. Non-pregnant women were divided into three groups according to their age: 20-40, 41-55 and 56-80 years, and women of reproductive age (20-40 years) as a contrast. To compare the reference range between pregnant women and women of reproductive age, age and body mass index (BMI) was matched between the two groups. The estimated gestational ages were determined by ultrasonic B-mode measurement of the fetal crown-rump length. All cases were followed by a survey of hospital medical record and telephone interview. Cases with thyroid or other systemic disorders, such as positive thyroid antibodies or thyroid nodules were excluded. The study protocol was approved by the Ethics Committee of the Affiliated Hospital of Jiangnan University (Wuxi, China) and all participants provided informed consent.

Sampling and analysis. Peripheral venous blood samples ( $3 \mathrm{ml}$ ) were collected from each participant. The samples were centrifuged for $5 \mathrm{~min}$ at $1,000 \mathrm{x} \mathrm{g}$. All serum obtained were immediately analyzed for FT3, FT4 and TSH at the magnetic microparticle chemiluminescence immunoassay (Unicel DXI800; Beckman Coulter, Inc., Brea, CA, USA). The interand intra-assay precision were all $<5.0 \%$ for FT3, FT4 and TSH.

Statistical analysis. Statistically analyzed was performed using the SPSS software version 17.0 (SPSS, Inc., Chicago, IL, USA). Data were described as mean \pm standard deviation. One-way analysis of variance was used to compare the levels of FT3, FT4 and TSH. Results of parameters were also expressed as median, IQR, P2.5 and P97.5. Post hoc analyses involved LSD and SNK tests. The limits of the reference intervals were calculated as P2.5 to P97.5. Comparisons among groups with different gestational ages were performed with Kruskal-Wallis test $(\mathrm{H}$ test) and comparisons between two different groups were compared with Wilcoxon test. $\mathrm{P}<0.05$ was considered to indicate a statistically significant difference.

\section{Results}

Serum thyroid hormone levels in non-pregnant women and normal pregnant women. A total of 4,903 pregnant women and 1,348 non-pregnant women fulfilled the criteria for selection and volunteered to participate in the study and 513 non-pregnant women (20-40 years) as controls and match their age and BMI with pregnant women. The parameters were described as mean \pm standard deviation for pregnant women according to gestational weeks and according to age for nonpregnant women. The mean age of 4,903 pregnant women was 27.5 years old (range, 20-40 years). The mean weight of pregnancy women was $58.1 \mathrm{~kg}$ (range, $41-85 \mathrm{~kg}$ ) and $58.0 \mathrm{~kg}$ in controls group (range, $40-79 \mathrm{~kg}$ ).

Table I presents the parameters of serum FT3, FT4 and TSH in non-pregnant women. A significant difference in concentration of FT3 levels (3.20 \pm 0.38 vs. $3.11 \pm 0.41, \mathrm{P}=0.014)$ was observed in the 56-85 year group compared with the 41-55 year group, but there was no significant difference between the other groups. A significant difference in FT4 levels $(0.83 \pm 0.12$ vs. $0.85 \pm 0.13$ and $0.86 \pm 0.12, \mathrm{P}=0.008$ and $\mathrm{P}=0.002$, respectively) was observed in the 41-55 year group compared with the 20-40 or 56-85 groups. TSH levels were significantly higher in the 56-85 year group than that of other groups $(\mathrm{P}=0.001$ and $\mathrm{P}=0.021$, respectively).

Table II demonstrates the mean values of thyroid hormone levels in normal pregnant women. From 8-14 to $\geq 37$ weeks, the concentrations of maternal serum FT3 and FT4 were continuous decline, and significant differences were identified between each group $(\mathrm{P}<0.05$ for all), except for the FT4 levels in 21-36 weeks were equivalent to that of the $\geq 37$ week groups $(\mathrm{P}>0.05)$. While TSH was increased and significant differences were identified between each group $(\mathrm{P}<0.05$ for all). Compared with the control groups (20-40 years, non-pregnant women), the mean values of FT3, FT4 and TSH were lower in pregnant women for all weeks ( $\mathrm{P}<0.05$ for all), except for the TSH levels in the $\geq 37$ week group ( $P>0.05$; Fig. 1$)$.

\section{Reference intervals of thyroid function in non-pregnant women and normal pregnant women. Tables III and IV present the median, P2.5-P97.5 and IQR of serum FT3, FT4 and TSH. The median of TSH levels demonstrated an overall increased trend from the 20-40 group to the 56-85 group in non-pregnant women and from the $8-14$ to the $\geq 37$ group in pregnant women. FT3 and FT4 levels demonstrated an overall decreased trend from the 8-14 to $\geq 37$ weeks group in pregnant women except for the FT4 in $\geq 37$ weeks. While in non-pregnant women, FT3 and FT4 levels were lower in the 41-55 age group than that of the other groups $(\mathrm{P}<0.05$ for all). The reference intervals of FT3, FT4 and TSH in 20-40 ages were 2.44-4.04 ng/1, $0.63-1.13 \mathrm{ng} / \mathrm{dl}$ and $0.74-5.13 \mathrm{uIU} / \mathrm{ml}$, respectively based on the 2.5-97.5 th percentiles, which were significantly higher than all normal pregnant women groups.}

\section{Discussion}

A previous study described thyroid diseases as the second most frequent endocrine disorder that affects women of reproductive 
Table I. Mean values of thyroid hormone in non-pregnant women.

\begin{tabular}{lclll}
\hline $\begin{array}{l}\text { Groups } \\
\text { (age range) }\end{array}$ & $\mathrm{n}$ & FT3 $(\mathrm{ng} / \mathrm{l})$ & FT4 $(\mathrm{ng} / \mathrm{dl})$ & $0.85 \pm 0.13^{\mathrm{b}}$ \\
\hline $20-40$ & 513 & $3.14 \pm 0.43$ & $0.83 \pm 0.12^{\mathrm{a}}$ & $2.20 \pm 1.09^{\mathrm{b}}$ \\
$41-55$ & 592 & $3.11 \pm 0.41^{\mathrm{b}}$ & $0.86 \pm 0.12^{\mathrm{b}}$ & $2.29 \pm 1.21^{\mathrm{b}}$ \\
$56-85$ & 193 & $3.20 \pm 0.38^{\mathrm{a}}$ & $0.84 \pm 0.13$ & $2.53 \pm 1.46^{\mathrm{a}}$ \\
Total & 1,298 & $3.14 \pm 0.41$ & $2.29 \pm 1.46$ \\
\hline
\end{tabular}

${ }^{\mathrm{a}} \mathrm{P}<0.05$ vs. values denoted with ${ }^{\mathrm{b}}$. The levels of FT3 in the 56-85 was higher than those in the 41-55 group. The levels of FT4 levels in the 41-55 were lower than those in the 20-40 and 56-85 groups, respectively. The levels of TSH in the 56-85 were higher than those at 20-40 and 41-55 groups, respectively. Data are presented as mean \pm standard deviation. FT3, free triiodothyronine; FT4, free thyroxine; TSH, thyroid stimulating hormone.

Table II. Mean values of thyroid hormone in normal pregnant women.

\begin{tabular}{|c|c|c|c|c|}
\hline $\begin{array}{l}\text { Gestational } \\
\text { weeks }\end{array}$ & $\mathrm{n}$ & FT3 (ng/l) & FT4 (ng/dl) & $\mathrm{TSH}(\mu \mathrm{IU} / \mathrm{ml})$ \\
\hline $8-14$ & 849 & $2.93 \pm 0.40^{\mathrm{a}}$ & $0.82 \pm 0.14^{\mathrm{a}}$ & $1.51 \pm 1.16^{\mathrm{a}}$ \\
\hline $15-20$ & 1,655 & $2.74 \pm 0.33^{\mathrm{a}}$ & $0.71 \pm 0.10^{\mathrm{a}}$ & $1.86 \pm 1.04^{\mathrm{a}}$ \\
\hline $21-36$ & 1,247 & $2.63 \pm 0.30^{\mathrm{a}}$ & $0.61 \pm 0.10^{\mathrm{b}}$ & $2.10 \pm 1.11^{\mathrm{a}}$ \\
\hline$\geq 37$ & 1,152 & $2.27 \pm 0.30^{\mathrm{a}}$ & $0.61 \pm 0.10^{\mathrm{b}}$ & $2.48 \pm 1.40^{\mathrm{a}}$ \\
\hline Total & 4,903 & $2.63 \pm 0.39$ & $0.68 \pm 0.13$ & $2.00 \pm 1.21$ \\
\hline
\end{tabular}

${ }^{\mathrm{a}} \mathrm{P}<0.05$ vs. values denoted with ${ }^{\mathrm{b}}$. From the $8-14$ to the $\geq 37$ group, the concentrations of maternal serum FT3 and FT4 reduced, whereas TSH levels were increased in normal pregnant women, except for the FT4 levels in the 21-36 week group were equivalent to that of the $\geq 37$ weeks. Data are presented as mean \pm standard deviation. FT3, free triiodothyronine; FT4, free thyroxine; TSH, thyroid stimulating hormone.

Table III. Reference intervals of thyroid function in non-pregnant women.

\begin{tabular}{|c|c|c|c|c|c|c|c|}
\hline \multirow{2}{*}{$\begin{array}{l}\text { Groups } \\
\text { (age range) }\end{array}$} & \multirow[b]{2}{*}{$\mathrm{n}$} & \multicolumn{2}{|c|}{ FT3 $(2.5-3.9 \mathrm{ng} / \mathrm{l})$} & \multicolumn{2}{|c|}{ FT4 (0.58-1.64 ng/dl) } & \multicolumn{2}{|c|}{ TSH (0.34-5.6 uIU/ml) } \\
\hline & & $\mathrm{M}(\mathrm{P} 2.5-\mathrm{P} 97.5)$ & IQR & $\mathrm{M}(\mathrm{P} 2.5-\mathrm{P} 97.5)$ & IQR & $\mathrm{M}(\mathrm{P} 2.5-\mathrm{P} 97.5)$ & IQR \\
\hline $20-40$ & 513 & $3.10(2.44-4.04)$ & 0.52 & $0.84(0.63-1.13)$ & 0.17 & $1.98(0.74-5.13)$ & 1.29 \\
\hline $41-55$ & 592 & $3.07(2.46-4.07)$ & 0.5 & $0.82(0.63-1.07)$ & 0.17 & $2.03(0.65-5.28)$ & 1.55 \\
\hline $56-85$ & 193 & $3.15(2.63-4.05)$ & 0.48 & $0.87(0.65-1.17)$ & 0.19 & $2.08(0.65-6.33)$ & 1.57 \\
\hline Total & 1,298 & $3.09(2.45-4.06)$ & 0.51 & $0.83(0.63-1.09)$ & 0.16 & $2.01(0.66-5.46)$ & 1.44 \\
\hline
\end{tabular}

age (8). In the present study, the authors investigated thyroid hormone changes in pregnant women and compared with control women of reproductive age in Jiangsu, China. Results of the study revealed that the levels of FT3 and FT4 declined and TSH increased continuously from 8-14 to $\geq 37$ weeks in normal pregnant women. Compared with controls, matched in their age and BMI, the mean values of FT3, FT4 and TSH were significantly lower in pregnant women in each group except for the TSH level in the $\geq 37$ weeks group.
Gestational thyroid dysfunction is a common and associated with maternal and child disease. When thyroid disorders remains untreated in a pregnant woman some disease can appear. Such examples include risk of miscarriage, hypertension, growth restriction and placental abruption (14-16). The basic premise for clinical management of thyroid disease in pregnancy is an accurate laboratory measurement of maternal serum thyroid hormones. Due to complicated physiological changes during pregnancy, thyroid hormones reference values 
Table IV. Reference intervals of thyroid function in normal pregnant women.

\begin{tabular}{|c|c|c|c|c|c|c|c|}
\hline \multirow{2}{*}{$\begin{array}{l}\text { Gestational } \\
\text { weeks }\end{array}$} & \multirow[b]{2}{*}{$\mathrm{n}$} & \multicolumn{2}{|c|}{ FT3 (2.5-3.9 ng/l) } & \multicolumn{2}{|c|}{ FT4 $(0.58-1.64 \mathrm{ng} / \mathrm{dl})$} & \multicolumn{2}{|c|}{ TSH (0.34-5.6 uIU/ml) } \\
\hline & & $\mathrm{M}(\mathrm{P} 2.5-\mathrm{P} 97.5)$ & IQR & $\mathrm{M}(\mathrm{P} 2.5-\mathrm{P} 97.5)$ & IQR & M (P2.5-P97.5) & IQR \\
\hline $8-14$ & 849 & $2.90(2.33-3.65)$ & 0.45 & $0.81(0.59-1.11)$ & 0.16 & $1.28(0.17-4.59)$ & 1.22 \\
\hline $15-20$ & 1,655 & $2.72(2.30-3.45)$ & 0.45 & $0.70(0.58-0.91)$ & 0.11 & $1.68(0.32-4.68)$ & 1.1 \\
\hline $21-36$ & 1,247 & $2.62(2.07-3.24)$ & 0.38 & $0.60(0.44-0.80)$ & 0.12 & $1.88(0.56-4.95)$ & 1.24 \\
\hline$\geq 37$ & 1,152 & $2.26(1.73-2.84)$ & 0.39 & $0.61(0.44-0.82)$ & 0.14 & $2.3(0.53-5.10)$ & 1.67 \\
\hline Total & 4,903 & $2.63(1.90-3.43)$ & 0.52 & $0.68(0.46-0.97)$ & 0.16 & $1.78(0.31-5.06)$ & 1.37 \\
\hline
\end{tabular}

In pregnant women, the median of FT3, FT4 and TSH levels demonstrated an overall increased trend from the 8-14 to $\geq 37$ gestational week groups, except for the FT4 levels in the 21-36 group, which was lower than that of $\geq 37$ weeks. Data are presented as mean \pm standard deviation. M, median; IQR, interquartile range; FT3, free triiodothyronine; FT4, free thyroxine; TSH, thyroid stimulating hormone.
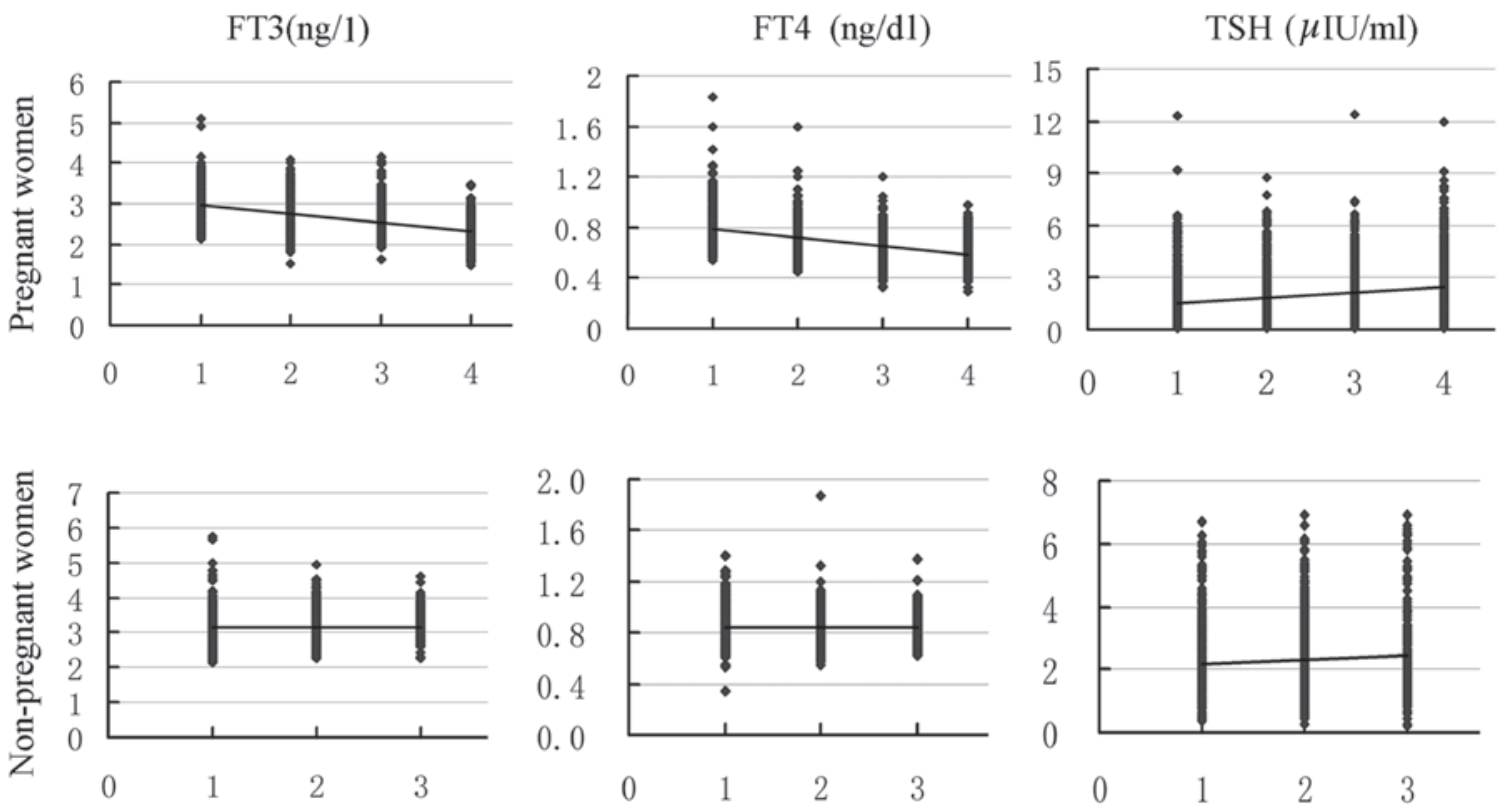

Figure 1. Fluctuations of thyroid hormone levels in normal pregnancies and non-pregnant women. From 8 -14 to $\geq 37$ weeks, the concentrations of maternal serum FT3 and FT4 continuous declined, while TSH was increased in normal pregnant women. From the ages of 20-40 to 56-85, the TSH concentration in non-pregnant women increased, but no trend for FT3 and FT4 was observed. 1, 8-14 weeks; 2, 15-20 weeks; 3, 21-36 weeks; 4, $\geq 37$ weeks in pregnant women and 1 , age $20-40 ; 2$, age $41-55 ; 3$, age $56-85$ years in non-pregnant women.

are different from those in non-pregnant state (17). Therefore, calculating pregnancy-specific reference intervals for thyroid hormone according to local region normal pregnant women database is required.

Previously, several studies have already described the role of thyroid function during pregnancy. Karmon et al (18) reported that thyroid function impacts the likelihood of pregnancy at the level of the oocyte. However, Moncayo et al (19) reported that thyroid function parameters in normal pregnancies do not differ from those in non-pregnant women in Austria. Elahi et al (20) reported that the mean FT4 level was decreased, and FT3 and TSH increased significantly in pregnant women compared to non-pregnant women in Pakistan. Therefore, the changes of thyroid hormone during pregnancy were substantially varied in different regions and remain controversial.
Investigation into thyroid function in pregnancy remains a matter of interest. The aim of the present study was to describe thyroid hormone changes during pregnancy and compare with control women of reproductive age. The current study indicated that the parameters of serum FT3,FT4 and TSH in non-pregnant women were close to that of the manufacturer's instructions, but significantly higher in old women (56-85 years) than 41-55 year-old-women. However, in normal pregnant women, the concentrations of maternal serum FT3 and FT4 continuous decline from 8-14 to $\geq 37$ weeks, and significant difference were found between each group $(\mathrm{P}<0.05$ for all $)$ except for FT4 in 21-36 weeks compared with $\geq 37$ weeks $(\mathrm{P}>0.05)$. While TSH were increased and significant difference were found between each group $(\mathrm{P}<0.05$ for all). Compared with the control, the mean values of FT3, FT4 and TSH were lower in pregnant women for all weeks $(\mathrm{P}<0.05$ for all) except for 
TSH in $\geq 37$ weeks $(\mathrm{P}>0.05)$. The present paper suggested a different conclusion to Moncayo et al (19) and Elahi et al (20). Notably, there was an obvious variation in different regions for thyroid hormone levels $(21,22)$. Therefore, it is necessary to establish the pregnancy-specific reference values for a local population. If pregnancy-specific reference values are used, thyroid hormone levels are more accurate to reflect maternal thyroid function.

During pregnancy, profound changes in thyroid physiology occur, resulting in different FT3, FT4 and TSH reference intervals compared to the non-pregnant state. Researchers are increasingly aware of the importance of evaluating maternal thyroid function during pregnancy by pregnancy-specific reference intervals, which reflected the changes of thyroid function in pregnant women more realistically (23-25). The previous study also gives the reference intervals of thyroid hormones, which were calculated as P2.5 to P97.5. FT3, FT4 and TSH reference intervals in control were 2.44$4.04 \mathrm{ng} / \mathrm{l}, 0.63-1.13 \mathrm{ng} / \mathrm{dl}$ and $0.74-5.13 \mathrm{uIU} / \mathrm{ml}$ based on 2.5-97.5 percentiles; similar to that of the manufacturer's instructions. In addition, this is significantly higher than that of all groups in normal pregnant women (Tables III and IV). If a non-pregnant reference interval is used, a number of maternal thyroid diseases could be potentially misclassified. Stricker et al (26) reported that 5.6-18.3\% of misclassification likely occurs in clinical practice due to the use of the non-pregnant normal population reference values as a basis for diagnosis.

Normal pregnant women are more likely to have lower thyroid hormones, which maybe a normal physiology changes during pregnancy. However, some studies have reported that thyroid insufficiency may be associated with adverse obstetric outcome and fetal neurodevelopment deficits. Therefore, it is important to know whether pregnant women have thyroid hormone deficiency and whether to supplement. Overall, the current reference intervals of thyroid hormone for non-pregnant women were unavailable for pregnant women. It may be advisable to establish pregnancy-specific reference intervals for thyroid hormone according to a local Chinese pregnant women database.

\section{Acknowledgements}

The present study was partially supported by grants from the Medical Science Foundation of Wuxi, Jiangsu Province (grant nos. YGZXZ1521 and YGZXH1402).

\section{References}

1. Allen EL and Miller EC: Thyroid function in normal pregnancy, pathologic pregnancy, and in patients on oral contraceptives. N C Med J 28: 417-429, 1967.

2. Alemu A, Terefe B, Abebe M and Biadgo B: Thyroid hormone dysfunction during pregnancy: A review. Int J Reprod Biomed (Yazd) 14: 677-686, 2016

3. Medici M, Korevaar TI, Visser WE, Visser TJ and Peeters RP: Thyroid function in pregnancy: What is normal? Clin Chem 61: 704-713, 2015.

4. Vila L, Velasco I, González S, Morales F, Sánchez E, Torrejón S, Soldevila B, Stagnaro-Green A and Puig-Domingo M: Controversies in endocrinology: On the need for universal thyroid screening in pregnant women. Eur J Endocrinol 170 R17-R30, 2013.
5. Knight BA, Shields BM, Hattersley AT and Vaidya B: Maternal hypothyroxinaemia in pregnancy is associated with obesity and adverse maternal metabolic parameters. Eur J Endocrinol 174: 51-57, 2016

6. Monen L, Pop VJ, Hasaart TH, Wijnen H, Oei SG and Kuppens SM: Increased maternal TSH and decreased maternal FT4 are associated with a higher operative delivery rate in low-risk pregnancies: A prospective cohort study. BMC Pregnancy Childbirth 15: 267, 2015.

7. León $\mathrm{G}$, Murcia M, Rebagliato M, Álvarez-Pedrerol M, Castilla AM, Basterrechea M, Iñiguez C, Fernández-Somoano A, Blarduni E, Foradada CM, et al: Maternal thyroid dysfunction during gestation, preterm delivery, and birthweight. The Infancia y Medio Ambiente Cohort, Spain. Paediatr Perinat Epidemiol 29: 113-122, 2015.

8. Rovet JF: The role of thyroid hormones for brain development and cognitive function. Endocr Dev 26: 26-43, 2014.

9. Wang W, Teng W, Shan Z, Wang S, Li J, Zhu L, Zhou J, Mao J, Yu X, Li J, et al: The prevalence of thyroid disorders during early pregnancy in China: The benefits of universal screening in the first trimester of pregnancy. Eur J Endocrinol 164: 263-268, 2011.

10. De Groot L, Abalovich M, Alexander EK, Amino N, Barbour L, Cobin RH, Eastman CJ, Lazarus JH, Luton D, Mandel SJ, et al: Management of thyroid dysfunction during pregnancy and postpartum: An Endocrine Society clinical practice guideline. J Clin Endocrinol Metab 97: 2543-2565, 2012.

11. Niwattisaiwong S, Burman KD and Li-Ng M: Iodine deficiency: Clinical implications. Cleve Clin J Med 84: 236-244, 2017.

12. Bulmus N, Ustuner I, Seda Guvendag Guven E, Kir Sahin F, Senturk S and Baydur Sahin S: Thyroid diseases in pregnancy: The importance of anamnesis. Pak J Med Sci 29: 1187-1192, 2013.

13. Lundqvist A, Johansson I, Wennberg A, Hultdin J, Högberg U, Hamberg K and Sandström H: Reported dietary intake in early pregnant compared to non-pregnant women - a cross-sectional study. BMC Pregnancy Childbirth 14: 373, 2014.

14. Spencer L, Bubner T, Bain E and Middleton P: Screening and subsequent management for thyroid dysfunction pre-pregnancy and during pregnancy for improving maternal and infant health. Cochrane Database Syst Rev 9: CD011263, 2015.

15. Benhadi N, Wiersinga WM, Reitsma JB, Vrijkotte TG and Bonsel GJ: Higher maternal TSH levels in pregnancy are associated with increased risk for miscarriage, fetal or neonatal death. Eur J Endocrinol 160: 985-991, 2009.

16. Giacobbe AM, Grasso R, Triolo O, Tonni G and Granese R: Thyroid diseases in pregnancy: A current and controversial topic on diagnosis and treatment over the past 20 years. Arch Gynecol Obstet 292: 995-1002, 2015.

17. Carreto-Molina N, García-Solís P, Solís-S JC, Robles-Osorio L, Hernández-Montiel HL and Vega-Malagón G: Importance of iodine in pregnancy. Arch Latinoam Nutr 62: 213-219, 2012.

18. Karmon AE, Batsis M, Chavarro JE and Souter I: Preconceptional thyroid-stimulating hormone levels and outcomes of intrauterine insemination among euthyroid infertile women. Fertil Steril 103: 258-63, 2015.

19. Moncayo R, Zanon B, Heim K, Ortner K and Moncayo H: Thyroid function parameters in normal pregnancies in an iodine sufficient population. BBA Clin 3: 90-95, 2015.

20. Elahi S, Rizvi NB and Nagra SA: Iodine deficiency in pregnant women of Lahore. J Pak Med Assoc 59: 741-743, 2009.

21. Duan Y, Peng L, Cui Y and Jiang Y: Reference intervals for thyroid function and the negative correlation between FT4 and $\mathrm{HbAlc}$ in pregnant women of west China. Clin Lab 61: 777-783, 2015.

22. Leung AM: Thyroid function in pregnancy. J Trace Elem Med Biol 26: 137-140, 2012.

23. Wang QW, Yu B, Huang RP, Cao F, Zhu ZQ, Sun DC and Zhou H: Assessment of thyroid function during pregnancy: The advantage of self-sequential longitudinal reference intervals. Arch Med Sci 7: 679-684, 2011.

24. Cohen O, Pinhas-Hamiel O, Sivan E, Dolitski M, Lipitz S and Achiron R: Serial in utero ultrasonographic measurements of the fetal thyroid: A new complementary tool in the management of maternal hyperthyroidism in pregnancy. Prenat Diagn 23: 740-742, 2003.

25. Krassas G, Karras SN and Pontikides N: Thyroid diseases during pregnancy: A number of important issues. Hormones (Athens) 14: 59-69, 2015.

26. Stricker R, Echenard M, Eberhart R, Chevailler MC, Perez V, Quinn FA and Stricker R: Evaluation of maternal thyroid function during pregnancy: the importance of using gestational age-specific reference intervals. Eur J Endocrinol 157: 509-514, 2007. 